TITLE:

\title{
Thermochromic VO[2] nanorods made by sputter deposition: Growth conditions and optical modeling
}

\author{
$\operatorname{AUTHOR}(\mathrm{S}):$ \\ Li, Shu-Yi; Namura, Kyoko; Suzuki, Motofumi; \\ Niklasson, Gunnar A.; Granqvist, Claes G.
}

\section{CITATION:}

Li, Shu-Yi ...[et al]. Thermochromic VO[2] nanorods made by sputter deposition: Growth conditions and optical modeling. Journal of Applied Physics 2013, 114(3): 033516.

\section{ISSUE DATE:}

2013

URL:

http://hdl.handle.net/2433/192291

\section{RIGHT:}

Copyright 2013 American Institute of Physics. This article may be downloaded for personal use only. Any other use requires prior permission of the author and the American Institute of Physics. 


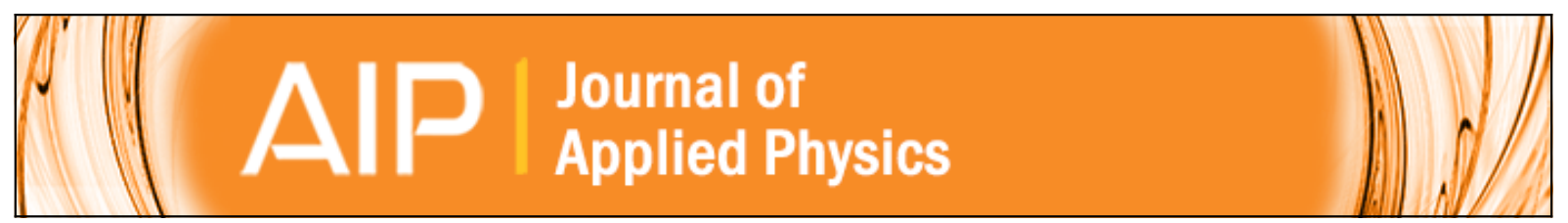

\section{Thermochromic VO2 nanorods made by sputter deposition: Growth conditions and optical modeling}

Shu-Yi Li, Kyoko Namura, Motofumi Suzuki, Gunnar A. Niklasson, and Claes G. Granqvist

Citation: Journal of Applied Physics 114, 033516 (2013); doi: 10.1063/1.4813876

View online: http://dx.doi.org/10.1063/1.4813876

View Table of Contents: http://scitation.aip.org/content/aip/journal/jap/114/3?ver=pdfcov

Published by the AIP Publishing

\section{Articles you may be interested in}

Thermochromic undoped and Mg-doped VO2 thin films and nanoparticles: Optical properties and performance limits for energy efficient windows

J. Appl. Phys. 115, 053513 (2014); 10.1063/1.4862930

Erratum: "Thermochromic VO2 nanorods made by sputter deposition: Growth conditions and optical modeling" [J. Appl. Phys. 114, 033516 (2013)]

J. Appl. Phys. 114, 239902 (2013); 10.1063/1.4848999

$\mathrm{SiC}$ nanorods of highly preferred orientation prepared by radio frequency magnetron sputtering

J. Vac. Sci. Technol. B 31, 060604 (2013); 10.1116/1.4829362

Bandgap widening in thermochromic Mg-doped VO2 thin films: Quantitative data based on optical absorption Appl. Phys. Lett. 103, 161907 (2013); 10.1063/1.4826444

Dependence of microstructure and thermochromism on substrate temperature for sputter-deposited VO 2 epitaxial films

J. Vac. Sci. Technol. A 15, 1113 (1997); 10.1116/1.580439

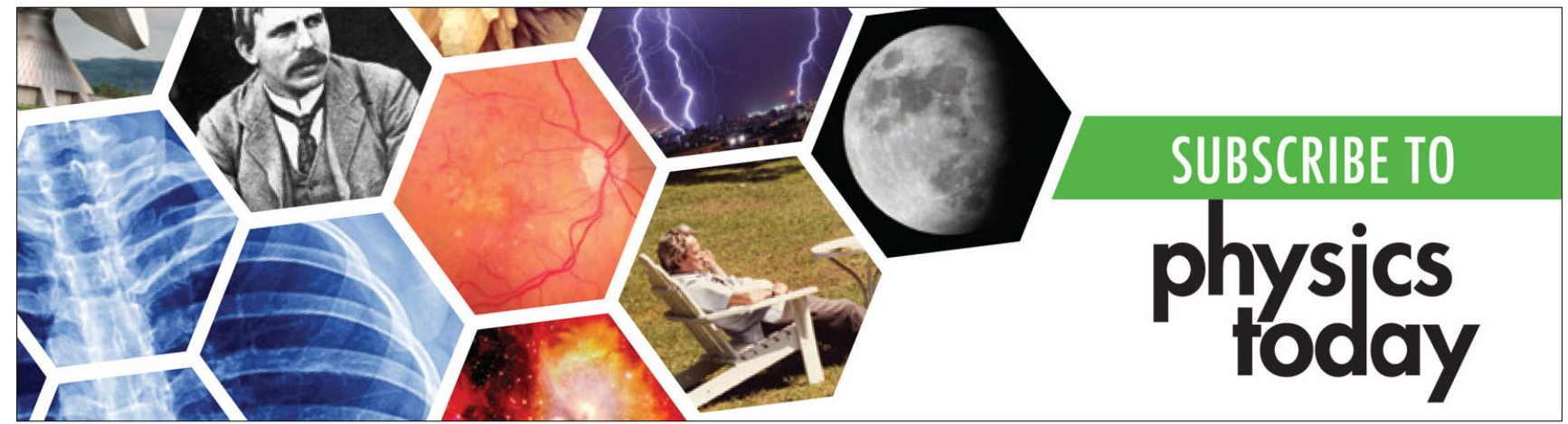




\title{
Thermochromic $\mathrm{VO}_{2}$ nanorods made by sputter deposition: Growth conditions and optical modeling
}

\author{
Shu-Yi Li, ${ }^{1, a)}$ Kyoko Namura, ${ }^{2, b)}$ Motofumi Suzuki, ${ }^{2}$ Gunnar A. Niklasson, ${ }^{1}$ \\ and Claes G. Granqvist ${ }^{1}$ \\ ${ }^{1}$ Department of Engineering Sciences, The Angström Laboratory, Uppsala University, P.O. Box 534, \\ SE-75121 Uppsala, Sweden \\ ${ }^{2}$ Department of Micro Engineering, Kyoto University-Katsura, C3 b4N01, Kyoto 615-8540, Japan
}

(Received 30 May 2013; accepted 26 June 2013; published online 17 July 2013)

Reactive dc magnetron sputtering onto glass-based substrates yielded deposits of thermochromic $\mathrm{VO}_{2}$ with well-developed nanorods and nanowires. Their formation was promoted by high substrate temperature (above $\sim 500^{\circ} \mathrm{C}$ ), sufficient film thickness, proper inlet of the reactive gas, dispersed gold "seeds," and pronounced substrate roughness. Rutherford back scattering ascertained mass thicknesses, scanning electron microscopy depicted the nanostructures, and glancing incidence $\mathrm{X}$-ray diffraction proved that single-phase $\mathrm{VO}_{2}$ was normally formed. Spectrophotometric measurements of total and diffuse transmittance and reflectance on $\mathrm{VO}_{2}$ thin films, at room temperature and $\sim 100{ }^{\circ} \mathrm{C}$, allowed us to determine complex dielectric functions below and above the "critical" temperature for thermochromic switching $\left(\sim 68^{\circ} \mathrm{C}\right)$. These data were then used in computations based on the Bruggeman effective medium theory applied to randomly oriented prolate spheroidal structural units to derive the optical properties of the deposits. Experimental and computed data on spectral absorptance were found to be in good qualitative agreement. (C) 2013 AIP Publishing LLC. [http://dx.doi.org/10.1063/1.4813876]

\section{INTRODUCTION}

This paper presents a comprehensive study on thermochromic $\mathrm{VO}_{2}$ nanorods and nanowires prepared by sputter deposition and discusses the critical nature of their growth conditions as well as modeling of their optical properties by effective medium theory.

Vanadium dioxide undergoes a reversible metal-insulator transition at a "critical" temperature $\tau_{c}$ of $68^{\circ} \mathrm{C} .{ }^{1}$ The lowtemperature phase is monoclinic, semiconducting, and infrared transparent, while the high-temperature phase is tetragonal, metallic, and infrared-reflecting. The exact nature of the metal-insulator transition has remained elusive and is of continuing scientific interest; recent work has emphasized the significance of electron-electron interactions associated with a Mott-Hubbard transition and/or electron-phonon interactions associated with a Peierls mechanism. ${ }^{2-9}$ The value of $\tau_{c}$ can be changed by substitutional doping, for example by replacing some vanadium by tungsten, ${ }^{10}$ and well-crystallized $\mathrm{W}_{x} \mathrm{~V}_{1-x} \mathrm{O}_{2}$ films with $x \approx 0.02$ can have $\tau_{c} \approx 20^{\circ} \mathrm{C} ;{ }^{11}$ doping with atomic hydrogen is another possibility. ${ }^{12}$ The magnitude of the resistance change at $\tau_{c}$ depends on the degree of crystallinity, and epitaxial films can display a difference of three to four orders of magnitude. ${ }^{13}$ The luminous transmittance can be boosted by magnesium substitution ${ }^{14,15}$ and by fluorination. ${ }^{16}$

The metal-insulator transition can be influenced by a variety of external parameters, and recent work has considered the effects of $\operatorname{strain}^{17-19}$ and lattice misfit with the

\footnotetext{
a) Author to whom correspondence should be addressed. Electronic mail: Shuyi.Li@angstrom.uu.se.

b) Japan Society for the Promotion of Science (JSPS) Research Fellow.
}

substrate, ${ }^{20,21}$ electric field or current activation, ${ }^{22-31}$ light irradiation, ${ }^{32-38}$ ion bombardment, ${ }^{39,40}$ and gaseous ambience. ${ }^{41}$ Considering the wealth of possibilities to modulate the properties of $\mathrm{VO}_{2}$-based thin films, it is not surprising that they are discussed for a vast number of applications such as thermochromic "smart" windows for energy efficient buildings, ${ }^{42-50}$ variable-thermal-emittance surfaces for thermal radiation control, ${ }^{51}$ oscillators and switches in (opto)electronics, ${ }^{25,26,34,52,53}$ transistors of different types, ${ }^{30,54,55}$ microcantilevers, ${ }^{56,57}$ memory elements,${ }^{58}$ infrared imaging devices $^{36}$ and spatial modulators for electromagnetic radiation, ${ }^{37,59}$ (micro)bolometers, ${ }^{60-63}$ and sensors for humidity ${ }^{64}$ and gas. ${ }^{41}$

It was recently realized that nanothermochromisminvolving $\mathrm{VO}_{2}$-based nanoparticles — can entail optical properties of primary interest for energy efficient fenestration. ${ }^{11,65-67}$ Consequently, it is of great importance to develop efficient methods to prepare such nanoparticles in large quantities and over extended surfaces. In fact, there have been numerous prior studies on $\mathrm{VO}_{2}$-based nanoparticles, and recent investigations have been conducted with hydrothermal/solvothermal/ colloidal techniques, ${ }^{27,49,50,64,68-108}$ vapor transport, ${ }^{56,109-115}$ anodization, ${ }^{116}$ polymer-assisted deposition, ${ }^{117,118}$ and templating. ${ }^{29,119}$ References to earlier studies on the manufacturing of nanostructured $\mathrm{VO}_{2}$-based materials can be found elsewhere. $^{65,66}$

Most of the work reported so far has dealt with materials preparations requiring long times for sample growth and/or post treatment or being suitable for small batches and small surfaces. However, it was recently demonstrated by Cheng et al. ${ }^{120}$ that "simple" thermal evaporation could yield highquality $\mathrm{VO}_{2}$ nanowires on roughened quartz substrates preferably heated to temperatures between 800 and $850^{\circ} \mathrm{C}$. In 
(a)

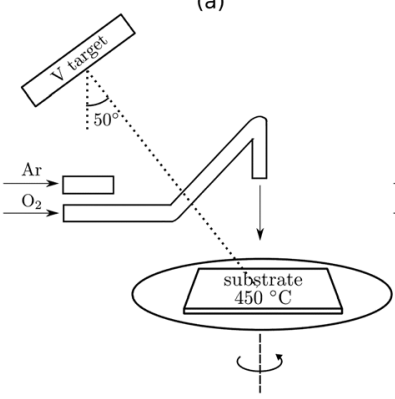

(b)

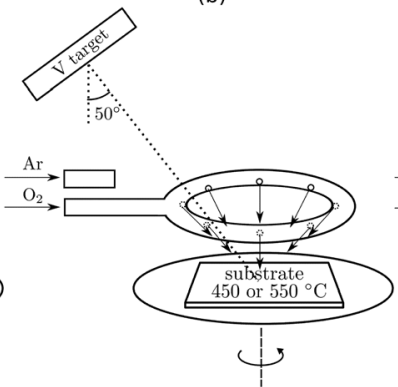

(c)

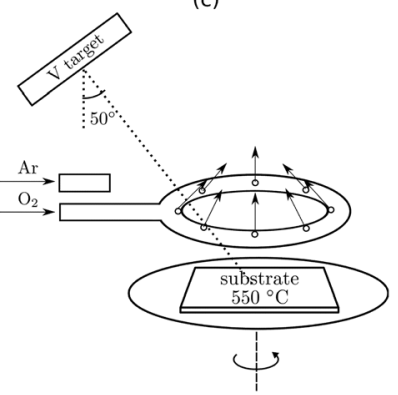

FIG. 1. Target-substrate geometry and provisions for gas inlet into the sputter chamber. the present work, we employ another physical vapor deposition technique, viz., reactive dc magnetron sputtering and demonstrate that $\mathrm{VO}_{2}$ nanowires can be grown onto coated or uncoated glass surfaces at temperatures of around $500^{\circ} \mathrm{C}$. It should be noted that magnetron sputtering is an extremely well established industrial technique for cost-efficient largearea deposition onto rigid and flexible substrates. ${ }^{121,122}$

\section{SAMPLE PREPARATION}

Nanorods and thin films of $\mathrm{VO}_{2}$ were prepared by reactive dc magnetron sputtering in a versatile deposition system based on a Balzers UTT 400 unit. The deposition chamber was evacuated to $6.3 \times 10^{-7} \mathrm{mbar}$, and $80 \mathrm{ml} / \mathrm{min}$ of argon and $5 \mathrm{ml} / \mathrm{min}$ of oxygen (both $99.997 \%$ ) were then introduced through mass-flow-controlled regulators; the total pressure was maintained at $1.2 \times 10^{-2}$ mbar. Sputtering took place from a 5-cm-diameter target of vanadium (99.5\%) at a power of $172 \mathrm{~W}$. The substrates were of three kinds: (i) 1-mm-thick glass slides (Thermo Scientific), (ii) such glass coated with 4.2-nm-thick gold films sputter-deposited at room temperature, and (iii) glass coated with $\sim 50$-nm-diameter silica "nanopillars" prepared by glancing angle deposition and having gold "caps," as reported elsewhere ${ }^{123}$ (cf. Fig. 5 below). The latter substrate was included since large surface roughness is known $^{120}$ to have a beneficial influence on $\mathrm{VO}_{2}$ growth. The gold films were non-uniform, as expected from their small mass thickness. ${ }^{124-127}$ The substrates were maintained at $450 \pm 10$ or $550 \pm 10^{\circ} \mathrm{C}$ during the depositions, as estimated from thermocouple-based recordings, and were rotated at 30 to $60 \mathrm{rpm}$. The substrate-target separation was $13 \mathrm{~cm}$, and the angle between the normals to the substrate and target was $50^{\circ}$. The $\mathrm{O}_{2}$ inlet was found to be important for the samples, and we used three arrangements as illustrated in Fig. 1: (a) a simple downwards-pointing tube located centrally above the substrate, (b) a perforated toroidal gas inlet with holes obliquely facing the substrate, and (c) the same gas inlet with the holes obliquely directed away from the substrate.

In all, we prepared more than 30 samples under a large variety of deposition conditions and selected 11 of them for closer examination. Their preparation characteristics are summarized in Table I, where the second, third, fourth, and fifth columns indicate specific gas inlet arrangement (cf. Fig. 1), substrate temperature $\tau_{s}$ during deposition, substrate type, and mass thickness, respectively. The final column indicates the prevailing film morphology, as illustrated and discussed below.

\section{STRUCTURE AND COMPOSITION}

\section{A. Rutherford backscattering spectrometry}

Samples 1, 2, 7, and 9 were investigated by Rutherford backscattering spectrometry (RBS) at the Uppsala Tandem Laboratory, employing $2 \mathrm{MeV}{ }^{4} \mathrm{He}$ ions backscattered at an angle of $170^{\circ}$. Figure 2 shows measured RBS spectra as well as data fitted to a model of the deposit-substrate system by use of the SIMNRA program. ${ }^{128}$

RBS data yield the stoichiometry and the number of atoms per area unit, which combined with thickness measurements (see below) can be used to determine the density of the sputter deposited films. The compact $\mathrm{VO}_{2}$ film, referred to as sample 1 , had $550 \times 10^{15}$ atoms $/ \mathrm{cm}^{2}$ and its observed

TABLE I. Fabrication parameters and morphology of $\mathrm{VO}_{2}$ samples. Gas inlets (a)-(c) refer to Fig. 1. Samples indicated by bold sample numbers were subjected to detailed analysis, including optical modeling.

\begin{tabular}{|c|c|c|c|c|c|}
\hline Sample No. & Gas inlet & Temperature $\left({ }^{\circ} \mathrm{C}\right)$ & Substrate & Mass thickness (nm) & Morphology \\
\hline 1 & a & 450 & Glass & 62.5 & Compact film Fig. 3(a) \\
\hline 2 & $\mathrm{~b}$ & 450 & Glass & 62.5 & Rough film with grains Fig. 3(b) \\
\hline 3 & $\mathrm{~b}$ & 550 & Glass & 34 & Small elongated grains Fig. 3(c) \\
\hline 4 & $\mathrm{~b}$ & 550 & Au/glass & 34 & Short rods Fig. 3(d) \\
\hline 5 & $\mathrm{~b}$ & 550 & Glass & 68 & Large elongated grains Fig. 3(e) \\
\hline 6 & $\mathrm{~b}$ & 550 & $\mathrm{Au} /$ glass & 68 & Moderate rods Fig. 3(f) \\
\hline 7 & $\mathrm{c}$ & 550 & Glass & 68 & Short rods Fig. 4(a)-4(c) \\
\hline 8 & $\mathrm{c}$ & 550 & $\mathrm{Au} /$ glass & 68 & Occasional long rods Figs. 4(d)-4(f) \\
\hline 9 & $\mathrm{c}$ & 550 & Glass & 102 & Dense long rods Figs. 4(g)-4(i) \\
\hline 10 & $\mathrm{c}$ & 550 & Au/glass & 102 & Long rods and long wires Figs. 4(j)-4(1) \\
\hline 11 & $\mathrm{a}$ & 450 & $\mathrm{Au} / \mathrm{SiO}_{2}$ nanopillars/glass & 34 & Long wires Fig. 5 \\
\hline
\end{tabular}



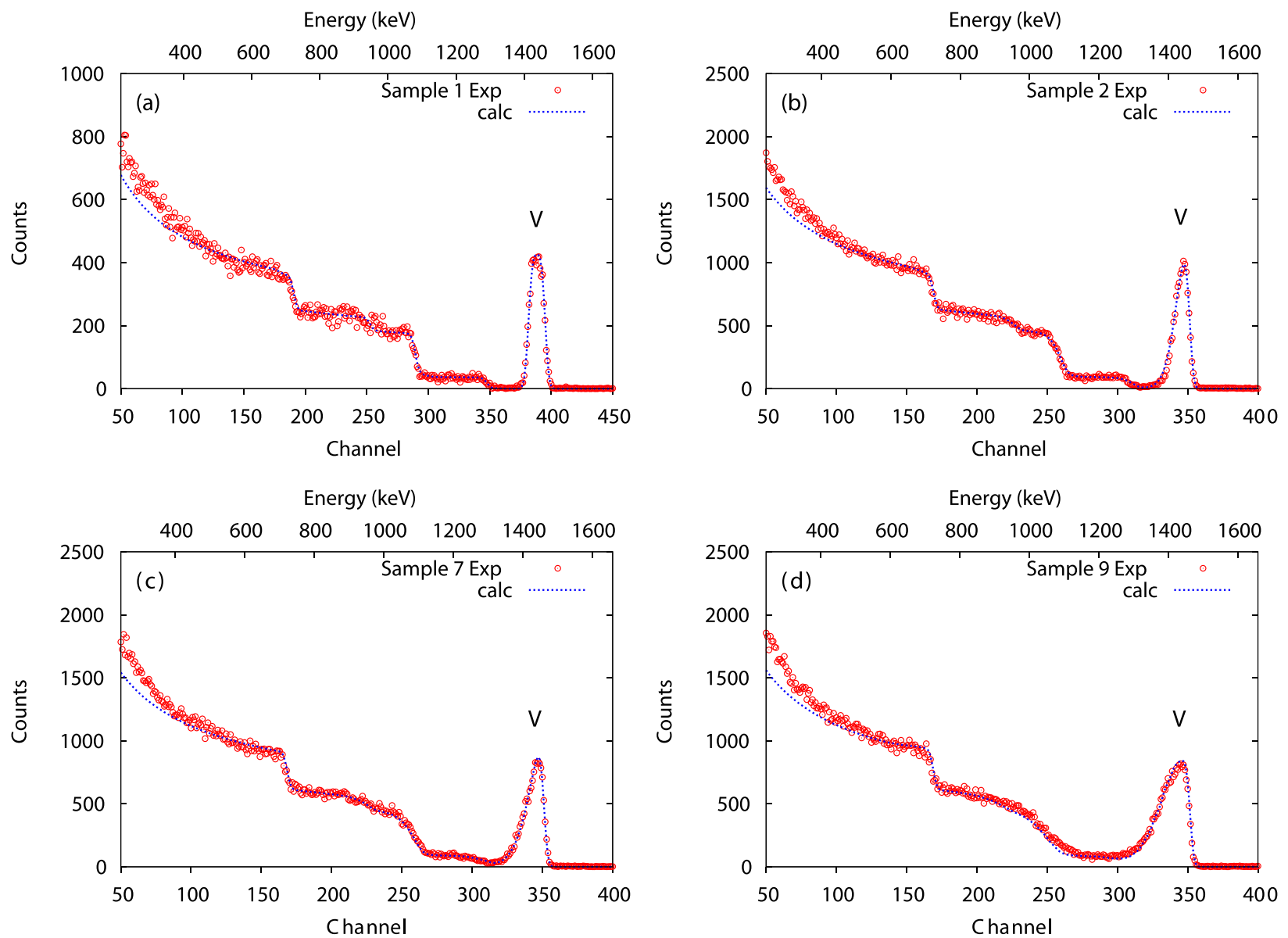

FIG. 2. Experimental (circles) and simulated (dotted curves) RBS data for four $\mathrm{VO}_{2}$ samples grown under the conditions stated in Table I.

thickness was $62.5 \mathrm{~nm}$, which gives a density of $4.04 \times 10^{3} \mathrm{~kg} / \mathrm{m}^{3}$. This is about $11 \%$ smaller than the density $4.571 \times 10^{3} \mathrm{~kg} / \mathrm{m}^{3}$ for bulk crystalline monoclinic $\mathrm{VO}_{2}$; a reduced density is expected in sputter-deposited films as a consequence of structural imperfections such as grain boundaries, vacancies, and incorporated gas molecules. Mass thicknesses $d$ for samples 2, 7, and 9 were determined from RBS data, assuming the same density as in sample 1, and mass thicknesses for the remaining samples were inferred from scaling with deposition time. These thicknesses are reported in Table I and are judged to be accurate to $\pm 5 \%$.

The analysis using the SIMNRA program allows assessment of sample inhomogeneity, and the asymmetrical vanadium peak exhibited by samples 2, 7, and 9 (Figs. 2(b)-2(d)) - especially for samples 7 and 9-gave evidence for strong fluctuations in the area density of vanadium atoms, as expected for deposits comprised of nanorods and nanowires. Sample 1, on the other hand, displayed a symmetrical vanadium peak (Fig. 2(a)), which signals homogeneity.

\section{B. Scanning electron microscopy}

All of the samples listed in Table I were studied by scanning electron microscopy (SEM), specifically using a LEO 1550 FEG Gemini instrument with an acceleration voltage of 10 to $15 \mathrm{kV}$. Imaging was done in three ways: (i) with the electron beam perpendicular to the sample surface, (ii) with the sample's surface normal tilted $70^{\circ}$ off the beam direction, and (iii) for the cross-section of a fractured sample. The latter measurements yield a "geometrical" sample thickness, which exceeds $d$ for samples with pronounced nanofeatures.

Figure 3 shows SEM micrographs for samples 1-6, which were prepared with downward-directed gas flow. Panels (a) and (b) refer to samples 1 and 2, which were deposited with approximately the same values of $\tau_{s} \approx 450{ }^{\circ} \mathrm{C}$ and $d \approx 62.5 \mathrm{~nm}$, on identical glass substrates, but with different arrangements for the gas inlet. The average grain sizes of the $\mathrm{VO}_{2}$ deposits differ significantly and were $\sim 28 \mathrm{~nm}$ for the tube inlet (Fig. 1(a)) and $\sim 45 \mathrm{~nm}$ for the toroidal inlet (Fig. 1(b)), implying that the morphology is critically dependent on the detailed deposition conditions. Samples 3 and 4, reported on in Figs. 3(c) and 3(d), have similar magnitudes of $\tau_{s} \approx 550{ }^{\circ} \mathrm{C}$ and $d \approx 34 \mathrm{~nm}$, employed the same type of gas inlet (Fig. 1(b)), but were grown on different types of substrates; sample 3 was deposited onto bare glass and sample 4 onto gold-seeded glass. Again the sample morphologies are markedly different, and the deposit on glass showed elongated grains with maximum lengths of $\sim 200 \mathrm{~nm}$, whereas the deposit on gold displayed grains with lengths up to $\sim 500 \mathrm{~nm}$. There is also a clear dependence on the deposit thickness, as found for samples 5 and 6 depicted in Figs. 3(e) and 3(f). These samples have $d \approx 68 \mathrm{~nm}$, i.e., they are twice as thick as samples 3 and 4 but were otherwise identical with regard to deposition parameters. The most noteworthy 


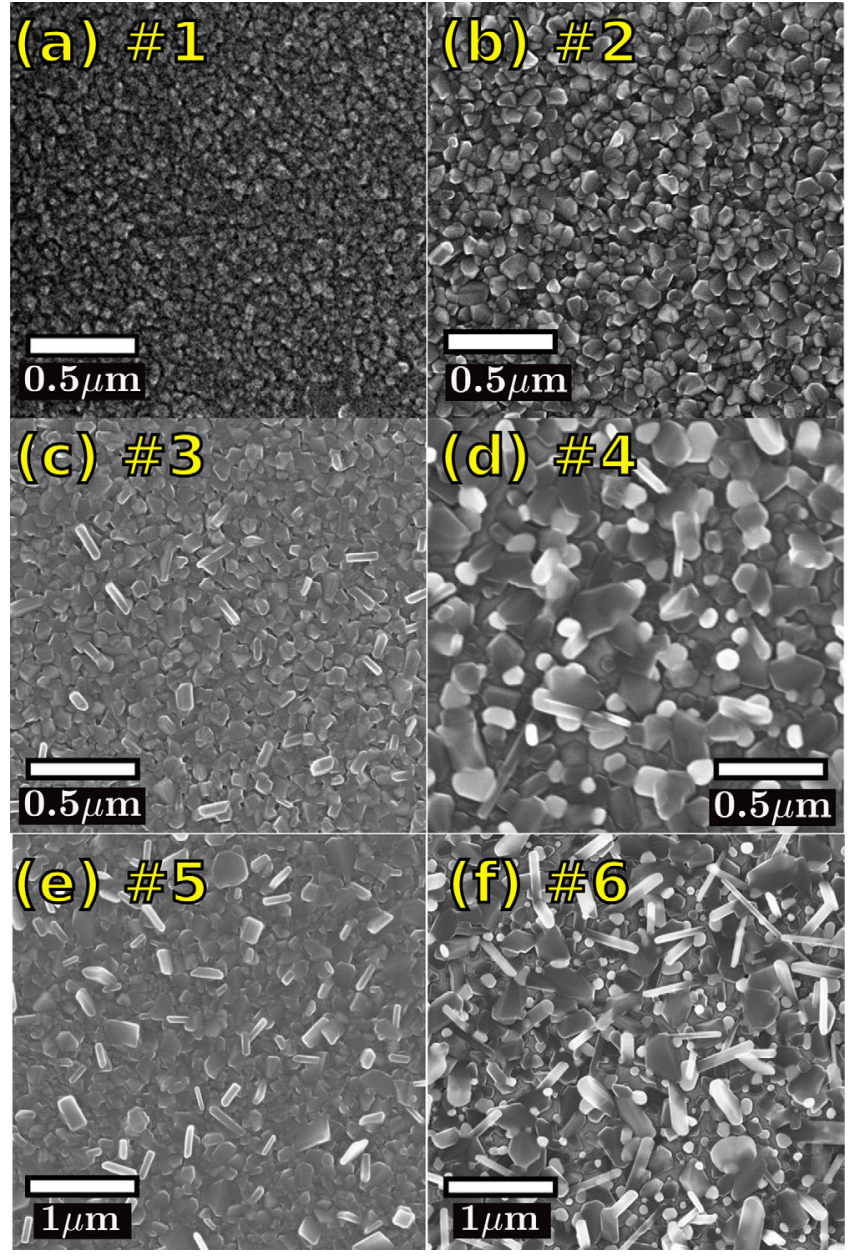

FIG. 3. Scanning electron micrographs (top views) for $\mathrm{VO}_{2}$ samples $1-6$ grown under the conditions stated in Table I. Note that the magnification of samples $1-4$ is different from that of samples 5 and 6 .

difference is between Figs. 3(d) and 3(f), referring to deposits on gold-seeded glass, and demonstrates that the deposit attains a decidedly rod-like character at $d \approx 68 \mathrm{~nm}$ whereas rods are much less prevalent at $d \approx 34 \mathrm{~nm}$. A close inspection of Fig. 3(d) shows that many of the rods have "caps" of gold, which suggests that $\mathrm{VO}_{2}$ has grown from underneath the gold seeds. The substrate temperature is another important factor, and a comparison of Fig. 3(b) obtained at $\tau_{s} \approx 450{ }^{\circ} \mathrm{C}$ with Figs. $3(\mathrm{c})$ and $3(\mathrm{e})$ obtained at $\tau_{s} \approx 550{ }^{\circ} \mathrm{C}$ shows that high substrate temperature facilitates a structure comprising elongated grains. Summarizing some of the main results in Fig. 3, one finds that the growth of $\mathrm{VO}_{2}$ nanorods is promoted by high substrate temperature, large deposit thickness, and gold seeding.

Figure 4 depicts SEM images recorded on samples 7-10 prepared at $\tau_{s} \approx 550{ }^{\circ} \mathrm{C}$ with obliquely upwards-directed gas flow (Fig. 1(c)). The first column of micrographs was taken with the electron beam perpendicular to the sample surface, the middle column with the sample's surface normal tilted $70^{\circ}$ off the beam direction, whereas the right-hand column shows cross-sections of fractured samples. The first and third rows of images refer to depositions onto bare glass and the second and fourth (bottom) rows refer to gold-seeded glass. Comparing the SEM micrographs in Fig. 4 for deposits on bare and gold-seeded glass, it is again apparent that gold promotes the formation of well-developed $\mathrm{VO}_{2}$ nanorods and nanowires. In particular, it is noteworthy that nanorods exceeding $5 \mu \mathrm{m}$ in length could be produced with considerable density for $\tau_{s} \approx 550{ }^{\circ} \mathrm{C}$ and $d \approx 102 \mathrm{~nm}$, as apparent from Fig. 4(j). Furthermore, it is interesting to compare data for samples 7 and 8 (Figs. 4(a), 4(b), 4(d), and 4(e)) with data for samples 5 and 6 (Figs. 3(e) and 3(f)); the former samples were prepared with a toroidal gas inlet with perforation directed obliquely away from the substrate (Fig. 1(c)), while the latter samples used the same gas inlet though with perforation obliquely facing the substrate (Fig. 1(b)), while all of the samples were made with the same values of $\tau_{s} \approx 550^{\circ} \mathrm{C}$ and $d \approx 68 \mathrm{~nm}$. This comparison demonstrates once again that details of the gas inlet play a pervasive role for the nanostructure of the deposits, and it is evident that nanorods and nanowires are better developed when the oxygen is directed obliquely away from the substrate. The cross-sectional SEM micrographs in Figs. 4(c), 4(f), 4(i), and 4(1) give striking evidence for nanorod and nanowire formation and also indicate that the deposits exhibit a two-layer structure with a highly porous top layer and a much more compact bottom layer.

Figure 5 shows cross-sectional views of sample 11 for which sputter deposition took place onto a substrate with silica "nanopillars" having gold "caps" as indicated in panel (c). The simple gas inlet in Fig. 1(a) was used, together with $\tau_{s} \approx 450{ }^{\circ} \mathrm{C}$. Despite the small mass thickness $d \approx 34 \mathrm{~nm}$, the deposit has developed nanowires more than two micrometers in length, which reiterates the large importance of the substrate conditions.

\section{X-ray diffractometry}

Grazing incidence X-ray diffraction (GIXRD) measurements were done for diffraction angles in the $10<2 \theta<80^{\circ}$ range and at room temperature by use of a Siemens D5000 Th-2Th instrument. Data are shown in Fig. 6 for samples 1, 2, 7, and 9; the diffractograms are found to agree well with the standard pattern for monoclinic $\mathrm{VO}_{2}$ with space group $P 21 / c{ }^{129}$ Rietveld refinement ${ }^{130}$ was performed on the GIXRD spectra using the PowderCell 2.3 program $^{131}$ and suggested that samples 7 and 9 are consistent with the March-Dollase model ${ }^{132}$ and exhibit moderate preferential growth in the (100) direction. Sample 9 displayed some additional tiny diffraction peaks for $2 \theta$. Those at $12.2^{\circ}, 25.88^{\circ}$, and $34.4^{\circ}$ may tentatively be associated with $\mathrm{V}_{2} \mathrm{O}_{5}$ (Refs. 133 and 134) or $\mathrm{V}_{2} \mathrm{O} .^{135}$

\section{OPTICAL PROPERTIES}

\section{A. Measured data and evaluated complex dielectric function}

Spectral total transmittance $T(\lambda)$ and reflectance $R(\lambda)$, as well as spectral diffuse transmittance $T_{d}(\lambda)$ and reflectance $R_{d}(\lambda)$, were measured in the $300<\lambda<2500 \mathrm{~nm}$ wavelength interval by use of a Perkin-Elmer Lambda 900 double-beam spectrophotometer equipped with a $\mathrm{BaSO}_{4}$-coated integrating sphere. Data were recorded for normal incidence at room temperature and at $100{ }^{\circ} \mathrm{C}$, where the latter temperature is 


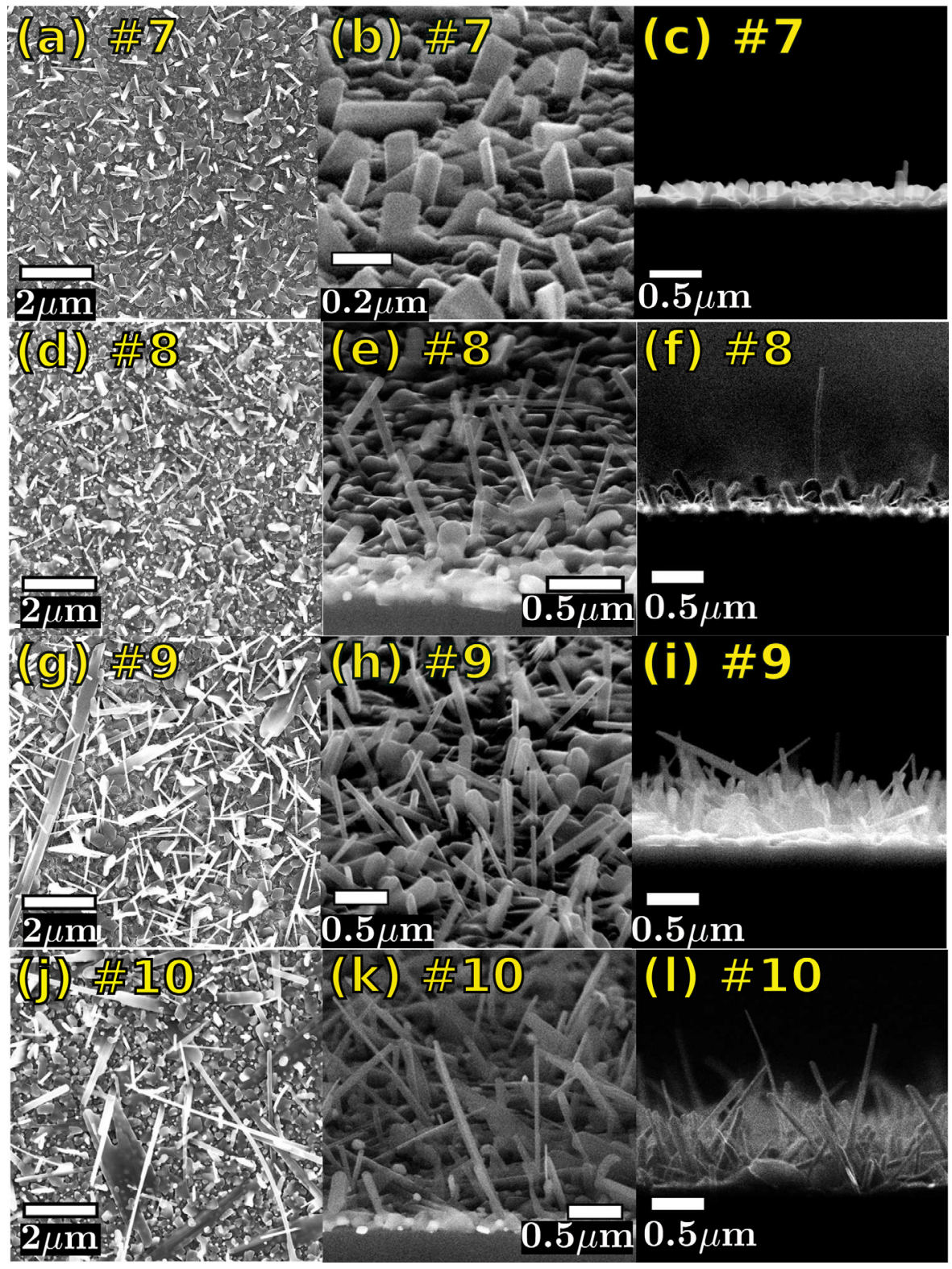

FIG. 4. Scanning electron micrographs for $\mathrm{VO}_{2}$ samples 7-10 grown under the conditions stated in Table I. Left-hand, middle, and right-hand columns refer to top views, imaging at $70^{\circ}$ between electron beam and sample normal, and cross-sectional views, respectively. Note that the magnifications differ among the various images.

well above $\tau_{c}$. The diffuse components represent light that was not specularly reflected or transmitted through the sample, as elaborated elsewhere. ${ }^{136}$ Our reflectance standard was a plate coated with $\mathrm{BaSO}_{4}$.
Figure 7 shows $T(\lambda)$ and $R(\lambda)$ for samples $1,2,7$, and 9. The former three of these have roughly the same mass thickness, whereas sample 9 is thicker. Thermochromism is evident, as expected, and the infrared transmittance is

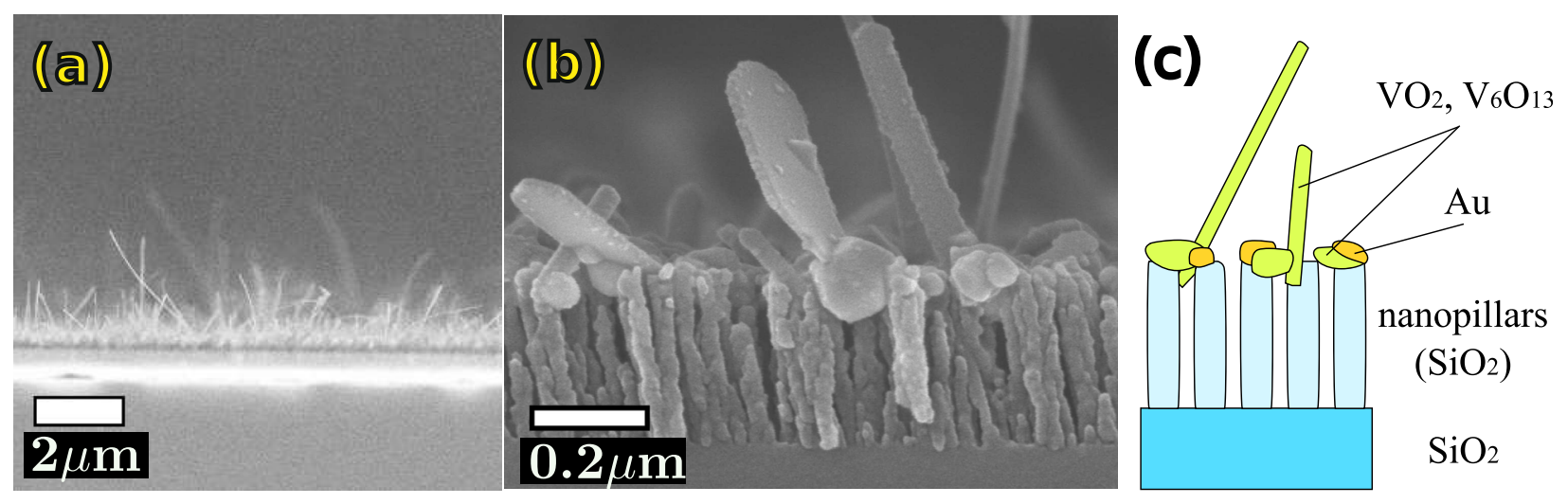

FIG. 5. Panels (a) and (b) show scanning electron micrographs (cross-sectional views) for $\mathrm{VO}_{2}$ sample 11, grown under the conditions stated in Table I, and provides an overview image as well as a magnification of the substrate and the lower part of some of the nanowires, respectively. Note that the magnifications are different for these two images. Panel (c) is a schematic rendition of the investigated sample. 


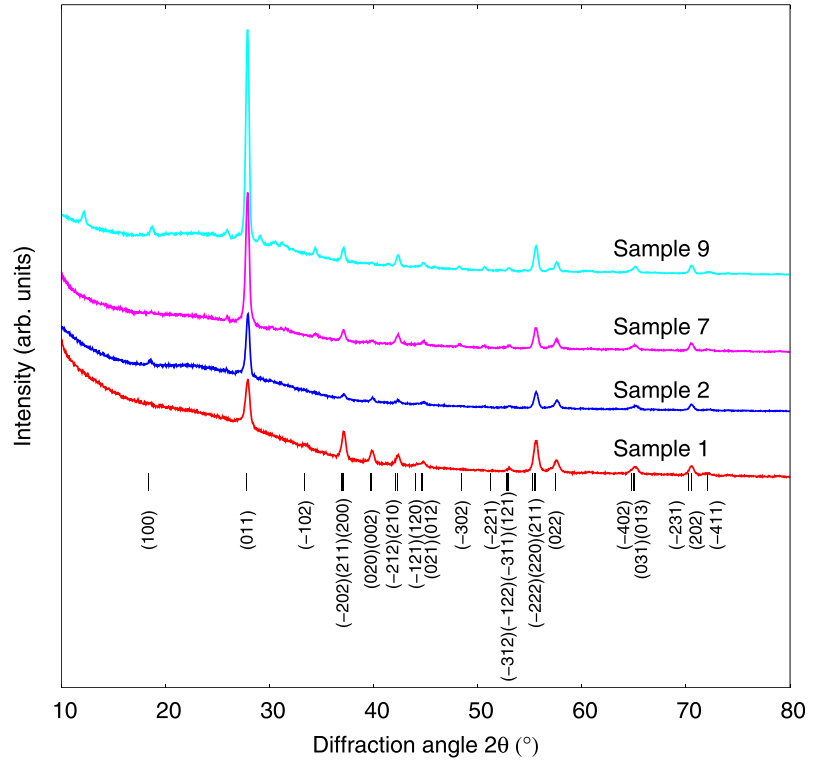

FIG. 6. Glancing incidence X-ray diffractograms taken at room temperature for $\mathrm{VO}_{2}$-based samples grown under the conditions stated in Table I. The diffraction features are assigned to the shown $(h k l)$ planes in monoclinic $\mathrm{VO}_{2}$.

decreased above $\tau_{c}$ while the infrared reflectance is then increased.

The magnitude of the diffuse components of the transmittance and reflectance is interesting since the analysis to be
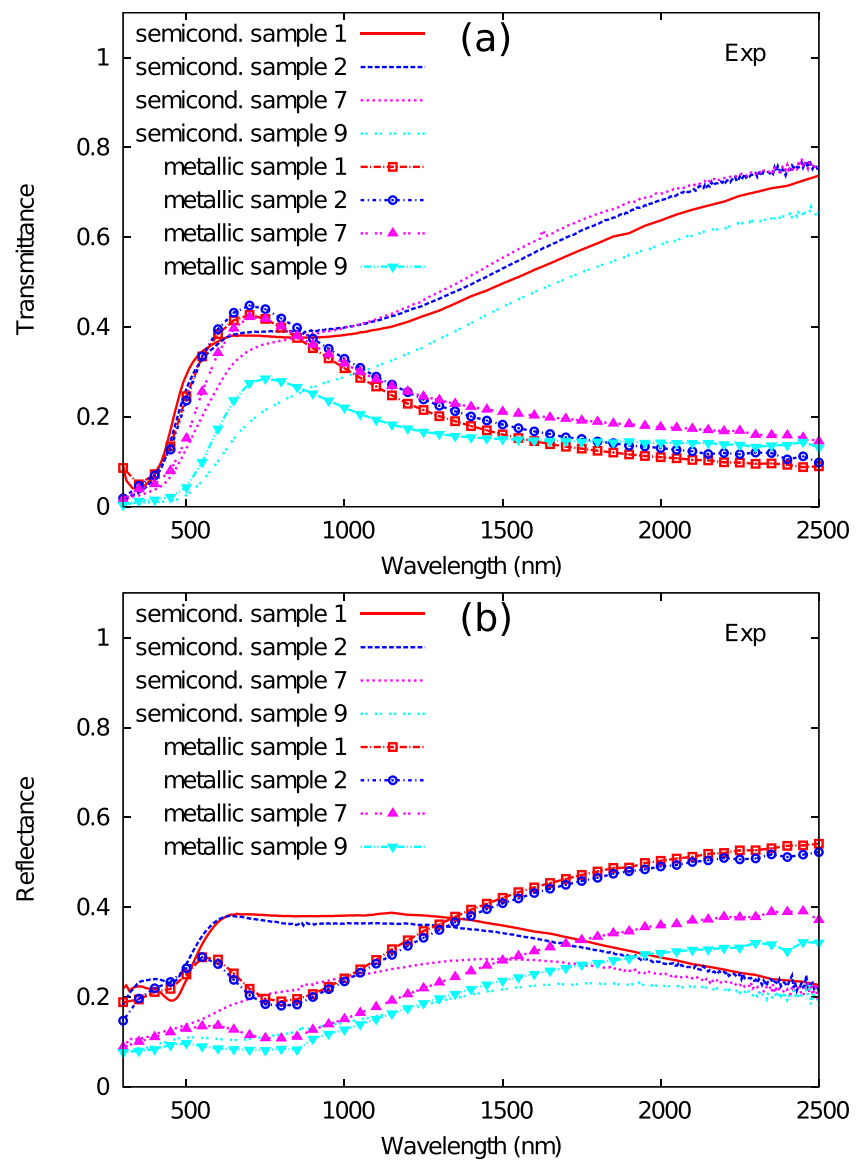

FIG. 7. Experimental spectral total transmittance (a) and reflectance (b) for $\mathrm{VO}_{2}$-based samples, grown under the conditions given in Table I, in semiconducting and metallic states. presented below does not account for them, and also because diffuse optical properties ("haze") may be undesired for practical applications such as in windows. Figure 8 reports $R_{d}(\lambda)$ and $T_{d}(\lambda)$ as measured at room temperature for samples 2,7 , and 9 and shows that the diffuse components can be as large as $\sim 12 \%$ for $R_{d}(\lambda)$; the spectra were peaked at a wavelength between 400 and $600 \mathrm{~nm}$. Samples 7 and 9 display welldeveloped nanofeatures, as seen in Fig. 4, and hence the optical scattering is by no means unexpected. The drop of the diffuse components at the shortest wavelengths is due to absorption in $\mathrm{VO}_{2}$, and the decline towards longer wavelengths occurs because the ratio between the size of the nanofeatures and the wavelength then gets progressively smaller.

Data on $T(\lambda)$ and $R(\lambda)$ for sample 1 were employed to compute spectral complex dielectric function $\varepsilon_{\mathrm{VO} 2}(\lambda)$ using commercial software ${ }^{137}$ with allowance for a rough surface layer on top of a compact base layer and also including effects of somewhat different reflectance data from the substrate side and the film side of the sample. Figure 9 shows the real and imaginary parts of $\varepsilon_{\mathrm{VO} 2}(\lambda)$ and compares our results with those earlier reported in the literature. ${ }^{138-142}$ Clearly the agreement among the data is satisfactory.

\section{B. Theoretical models}

SEM images of the $\mathrm{VO}_{2}$ deposits, shown in Figs. 3 and 4, were used to formulate structural models which were amenable to calculations of the optical properties for samples 1, 2, 7, and 9 by use of thin film optics. ${ }^{143}$ The modeling involves a number of uncertainties, and it does not aim at giving a fully quantitative theoretical representation of the optical properties but rather to explore whether theory and experiment can be brought in qualitative agreement.

Sample 1 is straightforward and can be viewed as a uniform slab of $\mathrm{VO}_{2}$ characterized by $d=62.5 \mathrm{~nm}$. Sample 2 shows signs of porosity, which we represent by $d=f_{b} d_{b}$, where $f_{b}$ denotes a "filling factor" for what we refer to as a "base layer"-i.e., the volume fraction occupied by $\mathrm{VO}_{2}-$ and $d_{b}$ is the geometrical thickness of this layer. Based on our SEM measurements, we set $d_{b}=70 \mathrm{~nm}$, which yields $f_{b}=0.89$. Samples 7 and 9 require more elaborate modeling

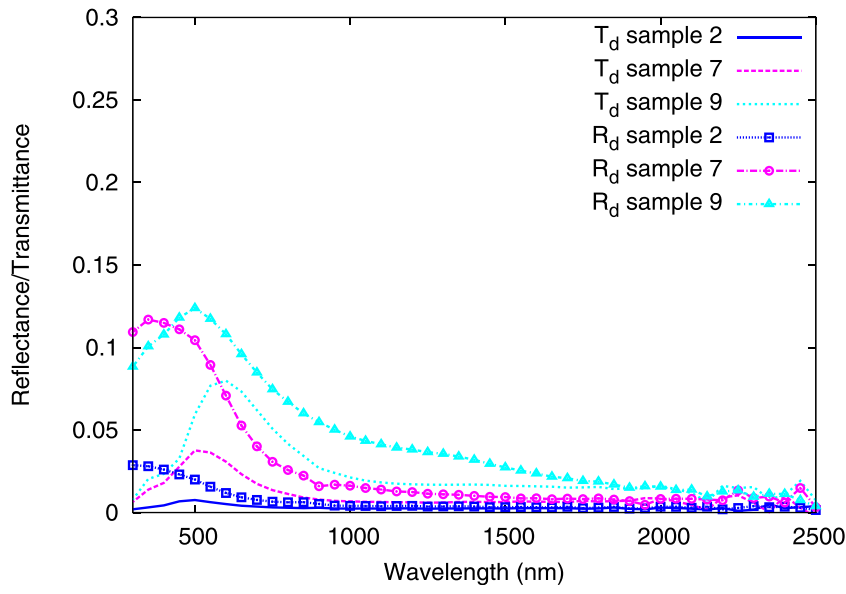

FIG. 8. Spectral diffuse reflectance $R_{d}$ and transmittance $T_{d}$ for $\mathrm{VO}_{2}$-based samples grown under the conditions stated in Table I. Data were taken at room temperature. 

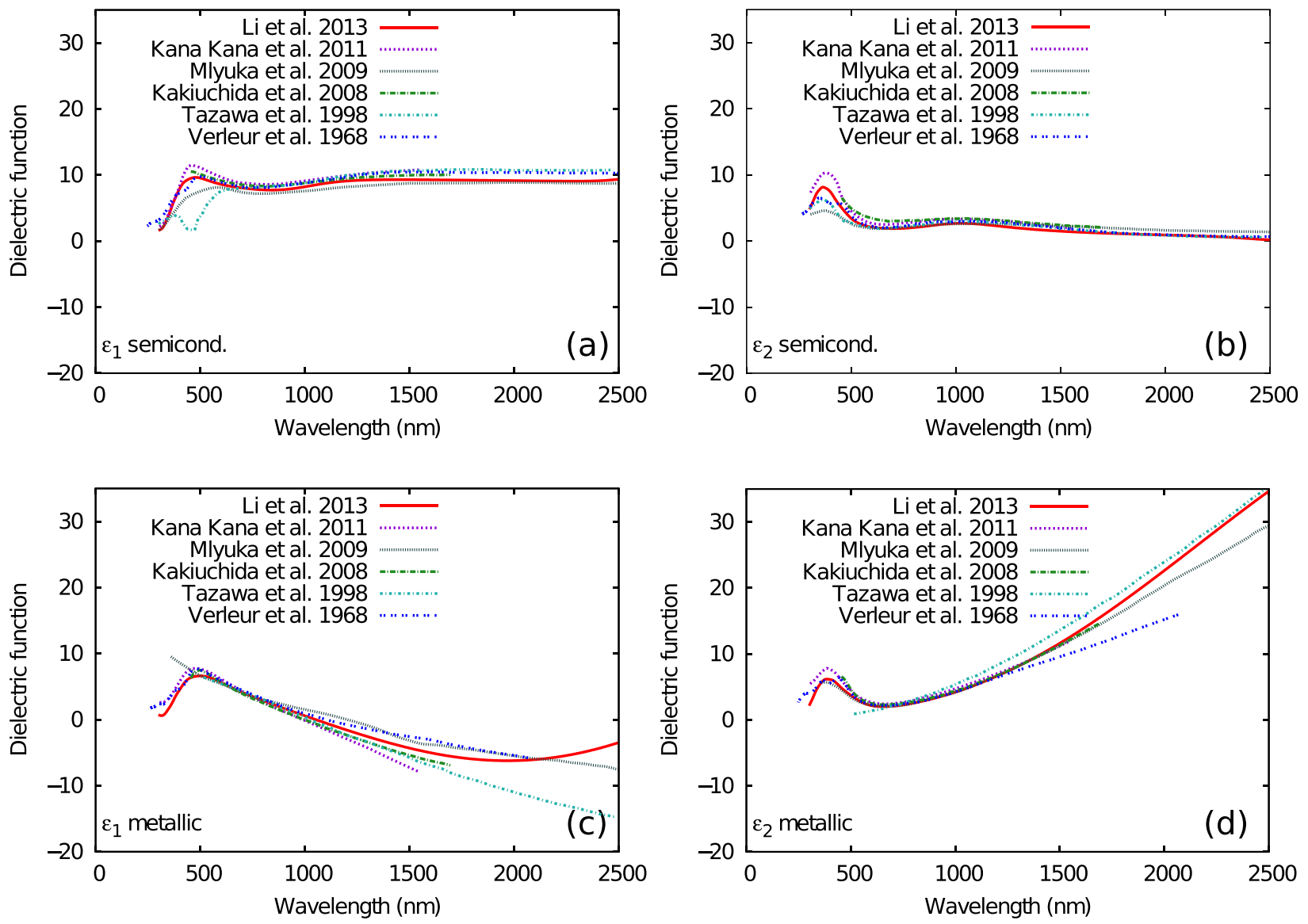

FIG. 9. Complex dielectric function, $\varepsilon \equiv \varepsilon_{1}+i \varepsilon_{2}$, of $\mathrm{VO}_{2}$ determined from sample 1 grown under the conditions stated in Table I. Upper and lower panels refer to semiconducting and metallic states, respectively. Also shown are data from the literature, specifically from Verleur et al. (Ref. 138), Tazawa et al. (Ref. 139), Kakiuchida et al. (Ref. 140), Mlyuka et al. (Ref. 141) and Kana Kana et al. (Ref. 142).

and must be described as two-layer structures with a top layer, characterized by a small filling factor $f_{t}$ and a thickness $d_{t}$, overlying a base layer represented by $f_{b}$ and $d_{b}$; these parameters obey the relationship

$$
d=f_{t} d_{t}+f_{b} d_{b} .
$$

The shapes and orientations of the nanofeatures are important too. We take the orientations to be random and the shape to be represented by the ratio between the largest and smallest axis of prolate spheroidal ("cigar shaped") units. This ratio is referred to as the "aspect ratio" and is denoted $m_{t}$ and $m_{b}$ for the top and base layers, respectively. Close examinations of the SEM images now allow us to assign approximate values to the various parameters, as summarized in Table II.

The optical properties of the top and base layers were accounted for by effective medium theory, which represents their dielectric functions by spatial averages over the properties of the particles $\varepsilon_{p}$ and of their surrounding medium $\varepsilon_{m} .{ }^{144}$ Specifically, we used the Bruggeman (BR) formulation, ${ }^{145}$ which is appropriate to a random mixture of topologically identical components. ${ }^{144}$ This topology seems most appropriate for the relatively dense base layers. Regarding the top layer, one may argue that the sparse $\mathrm{VO}_{2}$ nanoparticles are embedded in a continuous surrounding mediumwhich would motivate the use of the Maxwell-Garnett-type effective medium theory ${ }^{146}$ - but the values of $f_{t}$ are so small that the Bruggeman and Maxwell-Garnett theories are predicted to give practically indistinguishable results. Effective medium theory does not account for optical scattering, but the diffuse components of the reflectance and transmittance, shown in Fig. 8, were reassuringly small so as to make our theoretical approach meaningful.

The BR theory gives the effective dielectric function $\varepsilon^{B R}$ by

$$
\begin{gathered}
\varepsilon^{B R}=\varepsilon_{m} \frac{1+\frac{2}{3} f \alpha^{B R}}{1-\frac{1}{3} f \alpha^{B R}}, \\
\alpha^{B R}=\frac{1}{3} \sum_{i=1}^{3} \frac{\varepsilon_{p}-\varepsilon^{B R}}{\varepsilon^{B R}+L_{i}\left(\varepsilon_{p}-\varepsilon^{B R}\right)},
\end{gathered}
$$

TABLE II. Parameters for structural models of $\mathrm{VO}_{2}$-based samples grown under the conditions stated in Table I. $d, f$, and $m$ denote thickness, filling factor, and aspect ratio, respectively, for top $(t)$ and base $(b)$ layers.

\begin{tabular}{lcccccc}
\hline \hline Sample/Model & $d_{t}(\mathrm{~nm})$ & $f_{t}$ & $m_{t}$ & $d_{b}(\mathrm{~nm})$ & $f_{b}$ & $m_{b}$ \\
\hline 1 & $\ldots$ & $\ldots$ & $\ldots$ & 62.5 & 1 & $\ldots$ \\
2 & $\ldots$ & $\ldots$ & $\ldots$ & 70 & 0.893 & 1 \\
7 & 125 & 0.05 & 3 & 125 & 0.494 & 3 \\
9 & 500 & 0.01 & 10 & 200 & 0.485 & 10 \\
\hline \hline
\end{tabular}


where we use the same notation as in earlier papers. ${ }^{65,67,147,148}$ Here, the $L_{i}$ s represent triplets of depolarization factors with $L_{1}<L_{2}=L_{3}$ and obeying $\Sigma L_{i}=1$. For the present case of prolate spheroids, one has ${ }^{149}$

$$
\begin{gathered}
L_{1}=\frac{1-e^{2}}{2 e^{3}}\left(\ln \frac{1+e}{1-e}-2 e\right), \\
L_{2}=L_{3}=\left(1-L_{1}\right) / 2, \\
e=\left[1-m^{-2}\right]^{1 / 2} .
\end{gathered}
$$

As input parameters in Eqs. (2) and (3), we use $\varepsilon_{p} \equiv \varepsilon_{\mathrm{VO} 2}$ according to Fig. 9 together with $\varepsilon_{m}=1$. Thus, we do not invoke any size dependence in $\varepsilon_{p}$-as would be required for noble-metal-based particles ${ }^{147,150}$ - since the mean free path of the conduction electrons in $\mathrm{VO}_{2}$ is of the order of inter-atomic distances. ${ }^{151-153}$

\section{Comparison of theoretical and experimental data}

Figure 10 compares experimental and computed data, specifically the spectral absorptance $A(\lambda)=1-T(\lambda)-R(\lambda)$, for four samples. Concerning the experimental results in panel (a), we note that the relatively dense samples 1 and 2 show
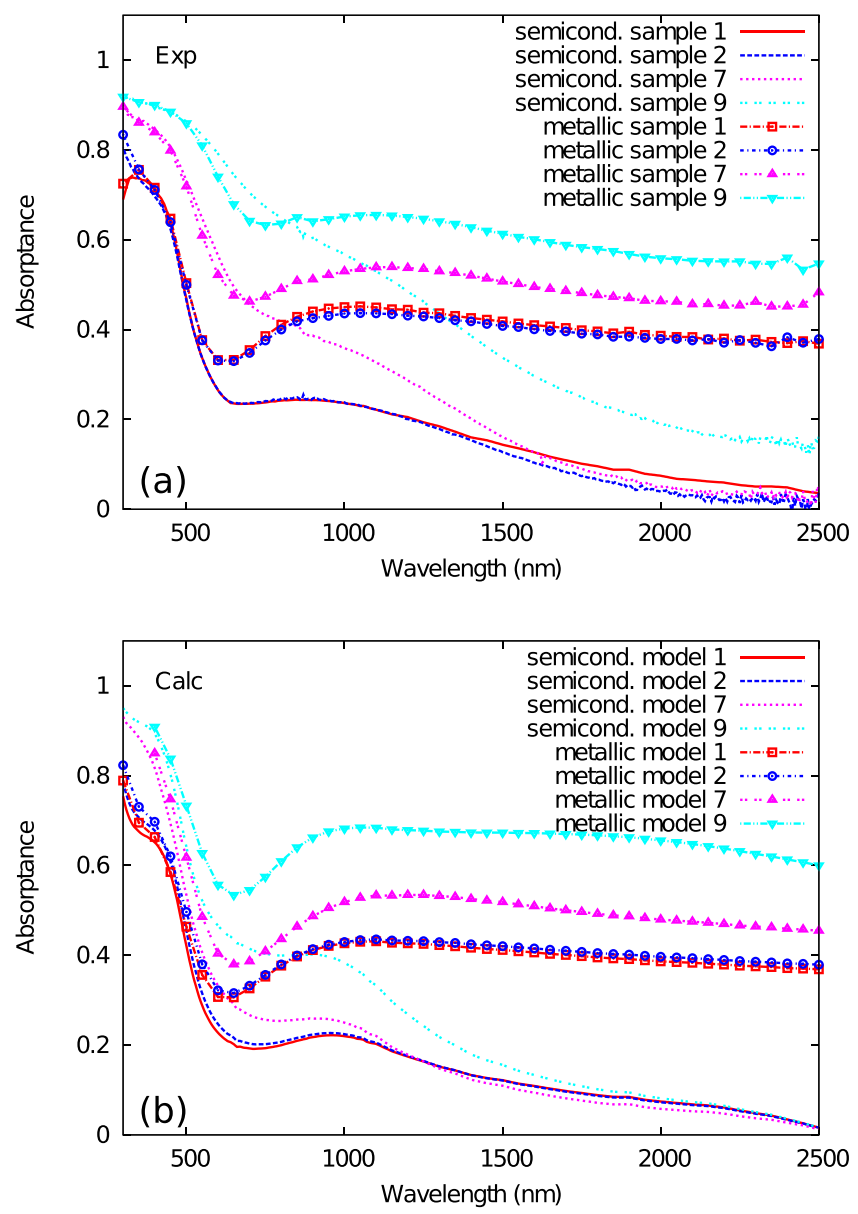

FIG. 10. Spectral absorptance for $\mathrm{VO}_{2}$-based samples in semiconducting and metallic states. Panel (a) shows experimental data for samples grown under the conditions stated in Table I, and panel (b) reports data obtained from the theoretical model computations and using model parameters given in Table II. almost identical absorptance over the whole measured spectral range for both semiconducting and metallic states. This can be compared with $A(\lambda)$ for sample 7 , containing nanorods, which shows increased absorption at $300<\lambda<1500 \mathrm{~nm}$ for the semiconducting state and a flat upwards shift in the whole spectral range for the metallic state. Sample 9, with nanorods and nanowires, displays an absorptance spectrum similar to that of sample 7 but with significantly increased values over the entire investigated wavelength range, as expected from the difference in mass thickness.

Calculated spectral absorptance is reported in Fig. 10(b) and shows good agreement with the experimental optical data for samples 1 and 2. Furthermore, the calculations exhibit an increasing trend of $A(\lambda)$ as the nanorod content is increased, which is consistent with the experimental data. Especially, the uniform upwards shift at $1000<\lambda<2500 \mathrm{~nm}$, which was apparent in the experimental absorptance for the metallic states of samples 7 and 9, is represented very well by the model. However, the computations display somewhat more pronounced spectral features than the experiments, especially for the semiconducting state. In particular, the absorptance in the ultraviolet and visible ranges for sample 9 clearly exceeds the corresponding calculated result. These effects may be due to the presence of defects, such as an excess of oxygen that is
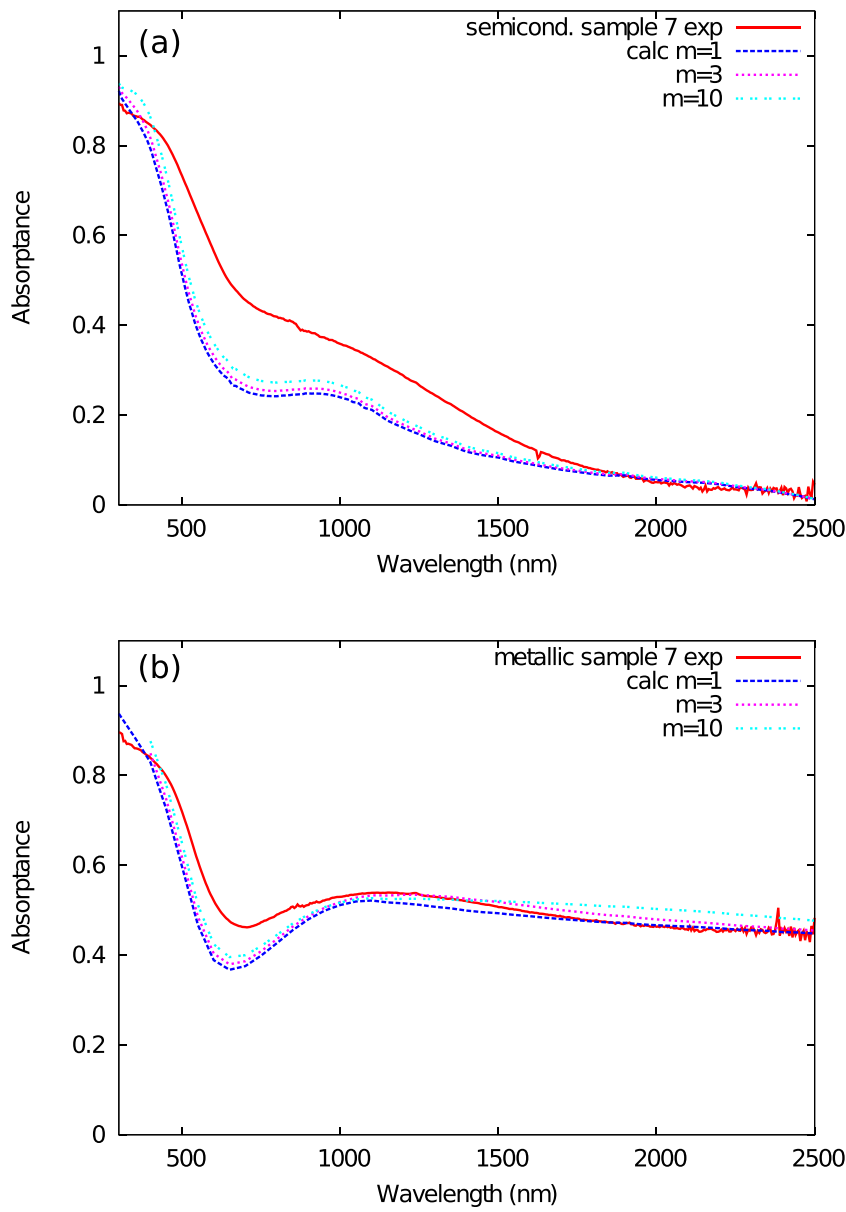

FIG. 11. Spectral absorptance measured for $\mathrm{VO}_{2}$-based sample 7, grown under the conditions shown in Table I, and obtained from the theoretical model computations and using $d_{t}, d_{b}, f_{t}$, and $f_{b}$ given in Table II together with the shown values of $m=m_{t}=m_{b}$. Panels (a) and (b) refer to semiconducting and metallic states, respectively. The experimental data were shown also in Fig. 10. 
likely to be present at high deposition temperature, ${ }^{154}$ or to absorption enhancement by multiple light-scattering.

It is worth noting that effective medium theory could no longer fully describe the optical properties in the short wavelength range for samples 7 and 9, which is understandable since the diffuse transmittance and reflectance were not negligible, as apparent from Fig. 8.

The theoretical models contain numerous parameters, and it is essential to ascertain that the results in Fig. 10 are neither fortuitous nor critically sensitive to the choice of parameter values. To this end we selected sample 7 for in-depth analysis and carried out calculations not only for $m_{t}=m_{b}=3$, as before, but also for aspects ratios of 1 (spheres) and 10. Figure 11 demonstrates that the role of the nanorod shape is minor. We also analyzed sample 7 by calculations regarding the effect of (i) having only the base layer on the glass substrate, (ii) having nothing but the top layer, and (iii) assuming that all of the $\mathrm{VO}_{2}$ is accounted for by the base layer. Figure 12 shows that the absorption of the top layer alone is not negligible, but when this layer is added to the base layer there is a reduction of the light available for absorption in the base layer, the net effect being that the total absorption in the metallic state within the doublelayer model yields merely a minor increase, on the scale of
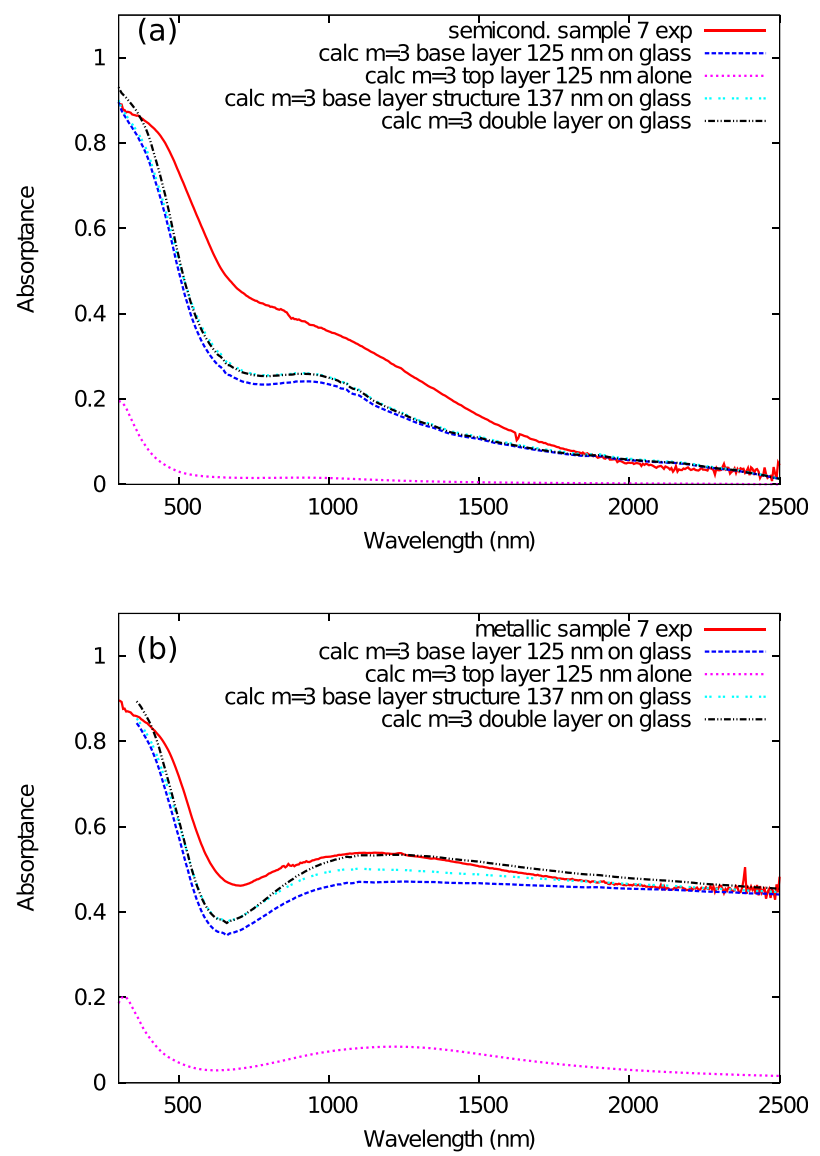

FIG. 12. Spectral absorptance measured for $\mathrm{VO}_{2}$-based sample 7, grown under the conditions shown in Table I, and obtained from the theoretical model computations and using the model parameters given in Table II (marked as "double layer on glass"). Also reported are computational results for a 125-nm-thick base layer on glass, a 125-nm-thick top layer alone, a 137-nm-thick film (with the total amount of $\mathrm{VO}_{2}$ encompassed by the double layer model) having the same structure as the base layer. Panels (a) and (b) refer to semiconducting and metallic states, respectively. The experimental data were shown also in Fig. 10. $\sim 0.04$ for the near-infrared absorption, compared with the case of having the base layer encompass all of the $\mathrm{VO}_{2}$. In the semiconducting state, the contribution of the top layer is even smaller. The main conclusion from the data presented in Figs. 11 and 12 is that the results inferred from Fig. 10 are reliable and not dependent on the details of the theoretical models.

\section{CONCLUSION AND REMARKS}

This work has demonstrated that reactive dc magnetron sputtering is a viable technique for preparing deposits of $\mathrm{VO}_{2}$ nanorods and nanowires. Their formation was found to be strongly influenced by several deposition conditions: (i) the substrate temperature should be relatively high and $550^{\circ} \mathrm{C}$ was superior to $450^{\circ} \mathrm{C}$, (ii) the deposit thickness should be large enough and our best data were obtained for the thickest layer with a mass thickness of $\sim 100 \mathrm{~nm}$, (iii) a thin layer of gold seeds promoted nanorod and nanowire formation, (iv) nanostructuring of the substrate facilitated nanowire formation, and (v) the "gas geometry"-i.e., the provisions for reactive gas inlet in the sputter chamber-was of large significance.

The growth conditions leading to $\mathrm{VO}_{2}$ nanorods and nanowires are unclear but may be related to the mechanisms underlying high-temperature glancing angle deposition (known as "HT-GLAD"). ${ }^{155-159}$ For the case of metal nanowires, the substrate temperature should be higher than about one third of the metal's melting point and the deposition angle typically should exceed $80^{\circ}$ with regard to the substrate normal. For the $\mathrm{VO}_{2}$ nanowires in the present study, we expect that the relative magnitude of the fluxes of vanadium atoms and oxygen molecules plays a decisive role. These aspects, and their interpretation in terms of HT-GLAD, will be treated in a forthcoming publication. The beneficial effect of gold seeds may be related to the well-known gold-catalyzed vapor-liquid-solid growth mode of semiconductor nanowires. ${ }^{160}$

The spectral absorptance of our deposits could be reconciled with an effective medium treatment based on the Bruggeman theory and using empirical data on the complex dielectric function of $\mathrm{VO}_{2}$.

\section{ACKNOWLEDGMENTS}

This work was financially supported by the Japan Society for the Promotion of Science (JSPS) through JSPS KAKENHI Grant No. 24-2362 and the JSPS Institutional Program for Young Researcher Overseas Visits. Further financial support was received from the Swedish Research Council. We acknowledge assistance with RBS measurements from Daniel Primetzhofer and the staff of the Tandem Accelerator Laboratory at Uppsala University and assistance with SEM measurements from Sadamu Kinoshita at Kyoto University. S.-Y.L. is grateful to Bozhidar Stefanov, Malin Johansson, Wei Xia, Ruitao Wen, and Anil Kumar Puri for discussions concerning XRD.

${ }^{1}$ F. J. Morin, Phys. Rev. Lett. 3, 34 (1959).

${ }^{2}$ M. M. Qazilbash, A. Tripathi, A. A. Schafgans, B.-J. Kim, H.-T. Kim, Z. Cai, M. V. Holt, J. M. Maser, F. Keilmann, O. G. Shpyrko, and D. N. Basov, Phys. Rev. B 83, 165108 (2011).

${ }^{3}$ A. S. Belozerov, M. A. Korotin, V. I. Anisimov, and A. I. Poteryaev, Phys. Rev. B 85, 045109 (2012). 
${ }^{4}$ J. S. Lee, K. Shibuya, M. Kawasaki, and Y. Tokura, Phys. Rev. B 85, 155110 (2012).

${ }^{5}$ M. Liu, H. Y. Hwang, H. Tao, A. C. Strikwerda, K. Fan, G. R. Keiser, A. J. Sternbach, K. G. West, S. Kittiwatanakul, J. Lu, S. A. Wolf, F. G. Omenetto, X. Zhang, K. A. Nelson, and R. D. Averitt, Nature 487, 345 (2012).

${ }^{6}$ A. Pergament and G. Stefanovich, Phase Transitions 85, 185 (2012).

${ }^{7}$ C. Si, W. Xu, H. Wang, J. Zhou, A. Ablat, L. Zhang, J. Cheng, Z. Pan, L. Fan, C. Zou, and Z. Wu, Phys. Chem. Chem. Phys. 14, 15021 (2012).

${ }^{8}$ Z. Tao, T.-R. T. Han, S. D. Mahanti, P. M. Duxbury, F. Yuan, and C.-Y. Ruan, Phys. Rev. Lett. 109, 166406 (2012).

${ }^{9}$ X. Zhong, P. LeClair, S. K. Sarker, and A. Gupta, Phys. Rev. B 86, 094114 (2012)

${ }^{10}$ J. B. Goodenough, J. Solid State Chem. 3, 490 (1971).

${ }^{11}$ S.-Y. Li, G. A. Niklasson, and C. G. Granqvist, Thin Solid Films 520, 3823 (2012).

${ }^{12}$ J. Wei, H. Ji, W. Guo, A. H. Nevidomskyy, and D. Natelson, Nat. Nanotechnol. 7, 357 (2012).

${ }^{13}$ Y. Cui and S. Ramanathan, J. Vac. Sci. Technol. A 29, 041502 (2011).

${ }^{14}$ N. R. Mlyuka, G. A. Niklasson, and C. G. Granqvist, Appl. Phys. Lett. 95, 171909 (2009).

${ }^{15}$ S. Hu, S.-Y. Li, R. Ahuya, C. G. Granqvist, K. Hermansson, G. A. Niklasson, and R. H. Scheicher, Appl. Phys. Lett. 101, 201902 (2012).

${ }^{16}$ K. A. Khan and C. G. Granqvist, Appl. Phys. Lett. 55, 4 (1989).

${ }^{17}$ V. N. Andreev and V. A. Klimov, Fiz. Tverd. Tela 53, 538 (2012) [Phys. Solid State 53, 577 (2011)].

${ }^{18}$ J. M. Atkin, S. Beerweger, E. K. Chavez, M. B. Raschke, J. Cao, W. Fan, and J. Wu, Phys. Rev. B 85, 020101 (2012).

${ }^{19}$ J. Laverock, L. F. J. Piper, A. R. H. Preston, B. Chen, J. McNulty, K. E. Smith, S. Kittiwatanakul, J. W. Lu, S. A. Wolf, P.-A. Glans, and J.-H. Guo, Phys. Rev. B 85, 081104 (2012).

${ }^{20}$ G. J. Kovács, D. Bürger, I. Skorupa, H. Reuther, R. Heller, and H. Schmidt, J. Appl. Phys. 109, 063708 (2011).

${ }^{21}$ H. Koo, S. Yoon, O.-J. Kwon, K.-E. Ko, D. Shin, S.-H. Bae, S.-H. Chang, and C. Park, J. Mater. Sci. 47, 6397 (2012).

${ }^{22}$ S. D. Ha, G. H. Aydogdu, B. Viswanath, and S. Ramanathan, J. Appl. Phys. 110, 026110 (2011)

${ }^{23}$ Y.-G. Jeong, H. Bernien, J.-S. Kyoung, H.-R. Park, H.-S. Kim, J.-W. Choi, B.-J. Kim, H.-T. Kim, K. J. Ahn, and D.-S. Kim, Opt. Express 19, 21211 (2011).

${ }^{24}$ Z. Yang, S. Hart, C. Ko, A. Yacoby, and S. Ramanathan, J. Appl. Phys. 110, 033725 (2011).

${ }^{25}$ T. Driscoll, J. Quinn, M. Di Ventra, D. N. Basov, G. Seo, Y.-W. Lee, H.-T. Kim, and D. R. Smith, Phys. Rev. B 86, 094203 (2012).

${ }^{26}$ B. A. Kruger, A. Joushaghani, and J. K. S. Poon, Opt. Express 20, 23598 (2012).

${ }^{27}$ Y. Liu, E. Uchaker, N. Zhou, J. Li, Q. Zhang, and G. Cao, J. Mater. Chem. 22, 24439 (2012).

${ }^{28}$ M. Nakano, K. Shibuya, D. Okuyama, T. Hatano, S. Ono, M. Kawasaki, Y. Iwasa, and Y. Tokura, Nature 487, 459 (2012).

${ }^{29}$ A. B. Pevtsov, A. V. Medvedev, D. A. Kurdyukov, N. D. Il'inskaya, V. G. Golubev, and V. G. Karpov, Phys. Rev. B 85, 024110 (2012).

${ }^{30}$ Z. Yang, Y. Zhou, and S. Ramanathan, J. Appl. Phys. 111, 014506 (2012).

${ }^{31}$ Y. Zhao, J. Hao, C. Chen, and Z. Fan, J. Phys.: Condens. Matter 24, 035601 (2012)

${ }^{32}$ H. Dachraoui, N. Müller, G. Obermeier, C. Oberer, S. Horn, and U. Heinzmann, J. Phys.: Condens. Matter 23, 435402 (2011).

${ }^{33}$ D. W. Ferrara, E. R. MacQuarrie, J. Nag, A. B. Kaye, and R. F. Haglund, Jr., Appl. Phys. Lett. 98, 241112 (2011).

${ }^{34}$ A. Pashkin, C. Kübler, H. Ehrke, R. Lopez, A. Halabica, R. F. Haglund, Jr., R. Huber, and A. Leitenstorfer, Phys. Rev. B 83, 195120 (2011).

${ }^{35}$ A. L. Semenov, Fiz. Tverd. Tela 53, 361 (2011) [Phys. Solid State 53, 386 (2011)].

${ }^{36}$ N. Dávila, R. Cabrera, and N. Sepúlveda, IEEE Photonics Technol. Lett. 24, 1830 (2012)

${ }^{37}$ P. A. Do, A. Hendaoui, E. Mortazy, M. Chaker, and A. Haché, Opt. Commun. 288, 23 (2013).

${ }^{38}$ G. Seo, B.-J. Kim, Y. W. Lee, and H.-T. Kim, Appl. Phys. Lett. 100, 011908 (2012)

${ }^{39}$ A. Gupta, R. Singhal, J. Narayan, and D. K. Avasthi, J. Mater. Res. 26, 2901 (2011)

${ }^{40}$ H. Hofsäss, P. Ehrhardt, H.-G. Gehrke, M. Brötzmann, U. Vetter, K. Zhang, J. Krauser, C. Trautmann, C. Ko, and S. Ramanathan, AIP Adv. 1, 032168 (2011).
${ }^{41}$ J. W. Byon, M.-B. Kim, M. H. Kim, S. Y. Kim, S. H. Lee, B. C. Lee, and J. M. Baik, J. Phys. Chem. C 116, 226 (2012).

${ }^{42}$ S. M. Babulanam, T. S. Eriksson, G. A. Niklasson, and C. G. Granqvist, Sol. Energy Mater. 16, 347 (1987).

${ }^{43}$ C. G. Granqvist, Sol. Energy Mater. Sol. Cells 91, 1529 (2007).

${ }^{44}$ M. Saeli, C. Piccirillo, I. P. Parkin, R. Binions, and I. Ridley, Energy Build. 42, 1666 (2010).

${ }^{45}$ M. Saeli, C. Piccirillo, I. P. Parkin, I. Ridley, and R. Binions, Sol. Energy Mater. Sol. Cells 94, 141 (2010).

${ }^{46}$ G. B. Smith and C. G. Granqvist, Green Nanotechnology: Solutions for Sustainability and Energy in the Built Environment (CRC Press, Boca Raton, FL, 2010).

${ }^{47}$ Z. Chen, Y. Gao, L. Kang, J. Du, Z. Zhang, H. Luo, H. Miao, and G. Tan, Sol. Energy Mater. Sol. Cells 95, 2677 (2011).

${ }^{48}$ Z. Zhang, Y. Gao, H. Luo, L. Kang, Z. Chen, J. Du, M. Kanehira, Y. Zhang, and Z. L. Wang, Energy Environ. Sci. 4, 4290 (2011).

${ }^{49}$ Y. Gao, H. Luo, Z. Zhang, L. Kang, Z. Chen, J. Du, M. Kanehira, and C. Cao, Nano Energy 1, 221 (2012).

${ }^{50}$ Y. Gao, S. Wang, L. Kang, Z. Chen, J. Du, X. Liu, H. Luo, and M. Kanehira, Energy Environ. Sci. 5, 8234 (2012).

${ }^{51}$ M. Benkahoul, M. Chaker, J. Margot, E. Haddad, R. Kruzelecky, B. Wong, W. Jamroz, and P. Poinas, Sol. Energy Mater. Sol. Cells 95, 3504 (2011).

${ }^{52}$ G. Seo, B.-J. Kim, Y. W. Lee, S. Choi, J.-H. Shin, and H.-T. Kim, Thin Solid Films 519, 3383 (2011).

${ }^{53}$ M. Soltani, M. Chaker, and J. Margot, Sci. Technol. Adv. Mater. 12, 045002 (2011)

${ }^{54}$ S. Sengupta, K. Wang, K. Liu, A. K. Bhat, S. Dhara, J. Wu, and M. M. Deshmukh, Appl. Phys. Lett. 99, 062114 (2011).

${ }^{55}$ Y. Zhou and S. Ramanathan, J. Appl. Phys. 111, 084508 (2012).

${ }^{56}$ A. Tselev, J. D. Budai, E. Strelcov, J. Z. Tischler, A. Kolmakov, and S. V. Kalinin, Nano Lett. 11, 3065 (2011).

${ }^{57}$ A. Rúa, R. Cabrera, H. Coy, E. Merced, N. Sepúlveda, and F. E. Fernández, J. Appl. Phys. 111, 104502 (2012).

${ }^{58}$ L. Pellegrino, N. Manca, T. Kanki, H. Tanaka, M. Biasotti, E. Bellingeri, A. S. Siri, and D. Marré, Adv. Mater. 24, 2929 (2012).

${ }^{59}$ S. B. Choi, J. S. Kyoung, H. S. Kim, H. R. Park, D. J. Park, B.-J. Kim, Y. H. Ahn, F. Rotermund, H.-T. Kim, K. J. Ahn, and D. S. Kim, Appl. Phys. Lett. 98, 071105 (2011).

${ }^{60}$ M. J. Coppinger, N. A. Sustersic, J. Kolodzey, and T. H. Allik, Opt. Eng. 50, 053206 (2011).

${ }^{61}$ L. N. Son, T. Tachiki, and T. Uchida, Jpn. J. Appl. Phys., Part 1 50, 025803 (2011).

${ }^{62}$ H. Takami, K. Kawatani, T. Kamki, and H. Tanaka, Jpn. J. Appl. Phys., Part 1 50, 055804 (2011).

${ }^{63}$ B. Wang, J. Lai, E. Zhao, H. Hu, Q. Liu, and S. Chen, Opt. Eng. 51, 074003 (2012).

${ }^{64}$ H. Yin, K. Yu, Z. Zhang, M. Zeng, L. Lou, and Z. Zhu, Electroanalysis 23, 1752 (2011).

${ }^{65}$ S.-Y. Li, G. A. Niklasson, and C. G. Granqvist, J. Appl. Phys. 108, 063525 (2010).

${ }^{66}$ S.-Y. Li, G. A. Niklasson, and C. G. Granqvist, J. Appl. Phys. 109, 113515 (2011).

${ }^{67}$ S.-Y. Li, G. A. Niklasson, and C. G. Granqvist, Appl. Phys. Lett. 99, 131907 (2011).

${ }^{68}$ S. Ji, F. Zhang, and P. Jin, J. Solid State Chem. 184, 2285 (2011).

${ }^{69}$ S. Ji, F. Zhang, and P. Jin, Sol. Energy Mater. Sol. Cells 95, 3520 (2011).

${ }^{70}$ S. Ji, F. Zhang, and P. Jin, Mater. Lett. 65, 708 (2011).

${ }^{71}$ W. Jiang, J. Ni, K. Yu, and Z. Zhu, Appl. Surf. Sci. 257, 3253 (2011).

${ }^{72}$ F. Y. Kong, M. Li, S. S. Pan, Y. X. Zhang, and G. H. Li, Mater. Res. Bull. 46, 2100 (2011).

${ }^{73} \mathrm{H}$. Li, P. He, Y. Wang, E. Hosono, and H. Zhou, J. Mater. Chem. 21, 10999 (2011)

${ }^{74}$ M. Li, F. Kong, Y. Zhang, and G. Li, Cryst. Eng. Comm. 13, 2204 (2011).

${ }^{75}$ M. Li, F. Kong, L. Li, Y. Zhang, L. Chen, W. Yan, and G. Li, Dalton Trans. 40, 10961 (2011).

${ }^{76}$ A. Llordes, A. T. Hammack, R. Buonsanti, R. Tangirala, S. Aloni, B. A. Helms, and D. J. Milliron, J. Mater. Chem. 21, 11631 (2011).

${ }^{77}$ Z. Lu, C. Li, and Y. Yin, J. Mater. Chem. 21, 14776 (2011).

${ }^{78}$ H. Miyazaki, K. Yoshida, S. Sasaki, N. Sakamoto, N. Wakiya, H. Suzuki, and T. Ota, J. Ceram. Soc. Jpn. 119, 522 (2011).

${ }^{79}$ J. Ni, W. Jiang, K. Yu, Y. Gao, and Z. Zhu, Electrochim. Acta 56, 2122 (2011). 
${ }^{80}$ J. Ni, W. Jiang, K. Yu, F. Sun, and Z. Zhu, Cryst. Res. Technol. 46, 507 (2011).

${ }^{81}$ S. Ni, H. Zeng, and X. Yang, J. Nanomater. 2011, 961389 (2011).

${ }^{82}$ Y. Sun, S. Jiang, W. Bi, R. Long, X. Tan, C. Wu, S. Wei, and Y. Xie, Nanoscale 3, 4394 (2011).

${ }^{83}$ L. Whittaker, J. M. Velazquez, and S. Banerjee, Cryst. Eng. Comm. 13, 5328 (2011)

${ }^{84}$ L. Whittaker, T.-L. Wu, C. J. Patridge, S. Sambandamurthy, and S. Banerjee, J. Mater. Chem. 21, 5580 (2011).

${ }^{85} \mathrm{C}$. Wu, X. Zhang, J. Dai, J. Yang, Z. Wu, S. Wie, and Y. Xie, J. Mater. Chem. 21, 4509 (2011).

${ }^{86}$ T.-L. Wu, L. Whittaker, S. Banerjee, and G. Sambandamurthy, Phys. Rev. B 83, 073101 (2011).

${ }^{87}$ H. Yin, M. Luo, K. Yu, Y. Gao, R. Huang, Z. Zhang, M. Zeng, C. Cao, and Z. Zhu, ACS Appl. Mater. Interfaces 3, 2057 (2011).

${ }^{88}$ H. Yin, J. Ni, W. Jiang, Z. Zhang, and K. Yu, Physica E 43, 1720 (2011).

${ }^{89}$ H. Yin, K. Yu, Z. Zhang, and Z. Zhu, Appl. Surf. Sci. 257, 8840 (2011).

${ }^{90}$ S. Zhang, B. Shang, J. Yang, W. Yan, S. Wei, and Y. Xie, Phys. Chem. Chem. Phys. 13, 15873 (2011).

${ }^{91}$ Y. Zhang, M. Fan, F. Niu, Y. Zhong, C. Huang, X. Liu, B. Wang, and H. Li, Micro Nano Lett. 6, 888 (2011).

${ }^{92}$ Y. Zhang, C. Chen, J. Zhang, L. Hu, W. Wu, Y. Zhong, Y. Cao, and X. Liu, Curr. Appl. Phys. 13, 47 (2013).

${ }^{93}$ Y. Zhang, M. Fan, W. Wu, L. Hu, J. Zhang, Y. Mao, C. Huang, and X. Liu, Mater. Lett. 71, 127 (2012).

${ }^{94}$ Y. Zhang, Y. Huang, J. Zhang, W. Wu, F. Niu, Y. Zhong, X. Liu, X. Liu, and C. Huang, Mater. Res. Bull. 47, 1978 (2012).

${ }^{95}$ Y. Zhang, M. Fan, X. Liu, G. Xie, H. Li, and C. Huang, Solid State Commun. 152, 253 (2012).

${ }^{96}$ Y. Zhang, M. Fan, F. Niu, W. Wu, C. Huang, X. Liu, H. Li, and X. Liu, Curr. Appl. Phys. 12, 875 (2012).

${ }^{97}$ Y. Zhang, M. Fan, M. Zhou, C. Huang, C. Chen, Y. Cao, G. Xie, H. Li, and X. Liu, Bull. Mater. Sci. 35, 369 (2012).

${ }^{98}$ Y. Zhang, F. Zhang, L. Yu, M. Fan, Y. Zhong, X. Liu, Y. Mao, and C. Huang, Colloids Surf., A 396, 144 (2012).

${ }^{99}$ Y. Zhang, J. Zhang, Y. Zhong, L. Yu, Y. Deng, C. Huang, and X. Liu, Appl. Surf. Sci. 263, 124 (2012).

${ }^{100}$ Q. Zhao, L. Jiao, W. Peng, H. Gao, J. Yang, Q. Wang, H. Du, L. Li, Z. Qi, Y. Si, Y. Wang, and H. Yuan, J. Power Sources 199, 350 (2012).

${ }^{101}$ L. Chen, C. Huang, G. Xu, L. Miao, J. Shi, J. Zhou, and X. Xiao, J. Nanomater. 2012, 491051.

${ }^{102}$ Y. Gao, C. Cao, L. Dai, H. Luo, M. Kanehira, Y. Ding, and Z. L. Wang, Energy Environ. Sci. 5, 8708 (2012).

${ }^{103}$ Y. Gao, S. Wang, H. Luo, L. Dai, C. Cao, Y. Liu, Z. Chen, and M. Kanehira, Energy Environ. Sci. 5, 6104 (2012).

${ }^{104}$ S. Milošević, I. Stojković, S. Kurko, J. Grbović Novaković, and N. Cvjetićanin, Ceram. Int. 38, 2313 (2012).

${ }^{105}$ C. Nethravathi, B. Viswanath, J. Michael, and M. Rajamath, Carbon 50, 4839 (2012).

${ }^{106}$ C. J. Partridge, L. Whittaker, B. Ravel, and S. Banerjee, J. Phys. Chem. C 116, 3728 (2012).

${ }^{107}$ X. Rui, D. Sim, C. Xu, W. Liu, H. Tan, K. Wong, H. H. Hng, T. M. Lim, and Q. Yan, RSC Adv. 2, 1174 (2012).

${ }^{108}$ L. Soltane, F. Sediri, and N. Gharbi, Mater. Res. Bull. 47, 1615 (2012).

${ }^{109}$ H. Guo, K. Chen, Y. Oh, K. Wang, C. Dejoie, S. A. Syed Asif, O. L. Warren, Z. W. Shan, J. Wu, and A. M. Minor, Nano Lett. 11, 3207 (2011).

${ }^{110}$ S. Löffler, E. Auer, M. Weil, A. Lugstein, and E. Bertagnolli, Appl. Phys. A 102, 201 (2011).

${ }^{111}$ E. Strelcov, A. V. Davydov, U. Lanke, C. Watts, and A. Kolmakov, ACS Nano 5, 3373 (2011)

${ }^{112}$ J. M. Wu and L. B. Liou, J. Mater. Chem. 21, 5499 (2011).

${ }^{113}$ R. Xie, C. T. Bui, B. Varghese, Q. Zhang, C. H. Sow, B. Li, and J. T. L. Thong, Adv. Funct. Mater. 21, 1602 (2011).

${ }^{114}$ S. Zhang, I. S. Kim, and L. J. Lauhon, Nano Lett. 11, 1443 (2011).

${ }^{115}$ J. I. Sohn, H. J. Joo, K. S. Kim, H. W. Yang, A.-R. Jang, D. Ahn, H. H. Lee, S. Cha, D. J. Kang, J. M. Kim, and M. E. Welland, Nanotechnology 23, 205707 (2012)

${ }^{116}$ Y. Yang, K. Lee, M. Zobel, M. Maćović, T. Unruh, E. Spiecker, and P. Schmulki, Adv. Mater. 24, 1571 (2012).

${ }^{117}$ L. Kang, Y. Gao, H. Luo, Z. Chen, J. Du, and Z. Zhang, Appl. Mater. Interfaces 3, 135 (2011).

${ }^{118}$ L. Kang, Y. Gao, H. Luo, J. Wang, B. Zhu, Z. Zhang, J. Du, M. Kanehira, and Y. Zhang, Sol. Energy Mater. Sol. Cells 95, 3189 (2011).
${ }^{119}$ D. A. Kurdyukov, S. A. Grudinkin, A. V. Nashchekin, A. N. Smirnov, E. Yu. Trofimova, M. A. Yagovkina, A. B. Pevtsov, and V. G. Golubev, Fiz. Tverd. Tela 53, 400 (2011) [Phys. Solid State 53, 428 (2011)].

${ }^{120}$ C. Cheng, K. Liu, B. Xiang, J. Suh, and J. Wu, Appl. Phys. Lett. 100, 103111 (2012).

${ }^{121}$ H. J. Gläser, Large Area Glass Coating (von Ardenne Anlagentechnik GmbH, Dresden, Germany, 2000).

${ }^{122}$ C. G. Granqvist, Sol. Energy Mater. Sol. Cells 99, 166 (2012).

${ }^{123}$ K. Namura, M. Suzuki, K. Nakajima, and K. Kimura, Opt. Lett. 36, 3533 (2011).

${ }^{124}$ S. Norrman, T. Andersson, C. G. Granqvist, and O. Hunderi, Phys. Rev. B 18, 674 (1978).

${ }^{125}$ G. B. Smith, G. A. Niklasson, J. S. E. M. Svensson, and C. G. Granqvist, J. Appl. Phys. 59, 571 (1986).

${ }^{126}$ P. C. Lansåker, J. Backholm, G. A. Niklasson, and C. G. Granqvist, Thin Solid Films 518, 1225 (2009).

${ }^{127}$ P. C. Lansåker, P. Petersson, G. A. Niklasson, and C. G. Granqvist, (to be published).

${ }^{128}$ M. Mayer, AIP Conf. Proc. 475, 541 (1999).

${ }^{129}$ Joint Center for Powder Diffraction Spectra, JCPDS Card No. 43-1051.

${ }^{130}$ H. M. Rietveld, J. Appl. Crystallogr. 2, 65 (1969).

${ }^{131}$ G. Nolze and W. Kraus, PowderCell 2.3 Program (Federal Institute for Materials Research and Testing, Berlin, Germany, 2000).

${ }^{132}$ W. A. Dollase, J. Appl. Crystallogr. 19, 267 (1986).

${ }^{133}$ Joint Center for Powder Diffraction Spectra, JCPDS Card No. 89-0612.

${ }^{134}$ Joint Center for Powder Diffraction Spectra, JCPDS Card No. 45-1074.

${ }^{135}$ Joint Center for Powder Diffraction Spectra, JCPDS Card No. 35-0361.

${ }^{136}$ D. Barrios, R. Vergaz, J. M. Sanchez-Pena, C. G. Granqvist, and G. A. Niklasson, Sol. Energy Mater. Sol. Cells 111, 115 (2013).

${ }^{137}$ M. Theiss, Hard and Software for Optical Spectroscopy (Dr.-BernhardKlein-Str. 110, D-52078 Aachen, Germany, 2002), see http:// www.mtheiss.com.

${ }^{138}$ H. W. Verleur, A. S. Barker, Jr., and C. N. Berglund, Phys. Rev. 172, 788 (1968).

${ }^{139}$ M. Tazawa, P. Jin, and S. Tanemura, Appl. Opt. 37, 1858 (1998).

${ }^{140}$ H. Kakiuchida, P. Jin, and M. Tazawa, Sol. Energy Mater. Sol. Cells 92, 1279 (2008).

${ }^{141}$ N. R. Mlyuka, G. A. Niklasson, and C. G. Granqvist, Phys. Status Solidi A 206, 2155 (2009).

${ }^{142}$ J. B. Kana Kana, J. M. Ndjaka, G. Vignaud, A. Gibaud, and M. Maaza, Opt. Commun. 284, 807 (2011).

${ }^{143} \mathrm{M}$. Born and E. Wolf, Principles of Optics, 7th ed. (Cambridge University Press, Cambridge, UK, 1999).

${ }^{144}$ G. A. Niklasson, C. G. Granqvist, and O. Hunderi, Appl. Opt. 20, 26 (1981).

${ }^{145}$ D. A. G. Bruggeman, Ann. Phys. (Leipz.) 416, 636 (1935).

${ }^{146}$ J. C. Maxwell-Garnett, Philos. Trans. R. Soc. London, Ser. A 203, 385 (1904); 205, 237 (1906).

${ }^{147}$ C. G. Granqvist and O. Hunderi, Phys. Rev. B 16, 3513 (1977).

${ }^{148}$ C. G. Granqvist and O. Hunderi, Phys. Rev. B 18, 2897 (1978).

${ }^{149}$ E. M. Lifshitz, L. D. Landau, and L. P. Pitaevskii, Electrodynamics of Continuous Media, 2nd ed. (Butterworth-Heinemann, Burlington, MA, 1984).

${ }^{150}$ U. Kreibig and M. Vollmer, Optical Properties of Metal Clusters (Springer, Berlin, Germany, 1995).

${ }^{151}$ P. B. Allen, R. M. Wentzcovitch, W. W. Schulz, and P. C. Canfield, Phys. Rev. B 48, 4359 (1993)

${ }^{152}$ K. Okazaki, S. Sugai, Y. Muraoka, and Z. Hiroi, Phys. Rev. B 73, 165116 (2006).

${ }^{153}$ A. Gentle, A. I. Maaroof, and G. B. Smith, Nanotechnology 18, 025202 (2007).

${ }^{154}$ C. Chen and Z. Fan, Appl. Phys. Lett. 95, 262106 (2009).

${ }^{155}$ M. Suzuki, K. Nagai, S. Kinoshita, K. Nakajima, K. Kimura, T. Okano, and K. Sasakawa, Appl. Phys. Lett. 89, 133103 (2006).

${ }^{156}$ M. Suzuki, K. Hamachi, K. Nagai, R. Kita, K. Nakajima, and K. Kimura, ECS Trans. 33(9), 41 (2010).

${ }^{157}$ M. Suzuki, R. Kita, H. Hara, K. Hamachi, K. Nagai, K. Nakajima, and K. Kimura, J. Electrochem. Soc. 157, K34 (2010).

${ }^{158}$ M. Suzuki, K. Hamachi, H. Hara, K. Nakajima, K. Kimura, C.-W. Hsu, and L.-J. Chou, Appl. Phys. Lett. 99, 223107 (2011).

${ }^{159}$ K. Hamachi, M. Suzuki, K. Nakajima, and K. Kimura, MRS Proc. 1059, 1059-KK04-09 (2007).

${ }^{160}$ R. S. Wagner and W. C. Ellis, Appl. Phys. Lett. 4, 89 (1964). 